\title{
Quality engineering of crumb rubber by minimizing rework using fuzzy FMEA
}

\author{
Khalida Syahputri ${ }^{1 *}$, Jelly Leviza ${ }^{1}$, Rahmi M Sari ${ }^{1}$, Indah Rizkya $\mathrm{T}^{1}$, Ikhsan Siregar ${ }^{1}$, and Mangara M Tambunan ${ }^{1}$ \\ ${ }^{1}$ Universitas Sumatera Utara, Department of Industrial Engineering, Faculty of Engineering, Medan, Indonesia
}

\begin{abstract}
The quality of crumb rubber has several grades according to Indonesian Rubber Standard (SIR). In crumb rubber process production, lots of products need to rework because it does not match with specified specifications. The types of rework product based on SIR that cause of defects such as hard, soft and dirt. However, the reworked products will produce crumb rubber with lower grade quality. This certainly affects the selling price of the crumb rubber. Also rework will incur additional production costs. Efforts that can be used to minimize the number of rework is to identify the factors that cause failure and determine the priority level of the risk of failure in the production process crumb rubber. It can be used is by using Fuzzy FMEA method. This method aims to get the risk of failure and the level of risk of failure during the crumb rubber production process. Fuzzy FMEA method also obtained the highest RPN value is equal to 489 for the risk of failure of engine dryer temperature is too high. Through the highest priority level of failure (RPN), company can determine the steps to make improvements during the production process to improve the quality of crumb rubber products.
\end{abstract}

\section{Introduction}

Companies always want to increase productivity in order to produce smooth production process. Production process that can be seen based on efficient production and can achieve the desired production target. Quality control in the process can help minimize the costs that arise, can also attract consumers because of the trust and consumer satisfaction of these products.

The problems that occur in this study are products that do not conform to the standards produced by the reworked product. Therefore it is necessary to improve the quality for each product using FMEA fuzzy method to see which process is the most error and provide the right information for the company.

FMEA is a systematic bottom-up approach for identifying potential critical failure modes of a manufacturing process or a product to provide key information for improvement and risk assessment [1]. FMEA is a widely used quality improvement and risk assessment tool in manufacturing industry. This tool combines the human knowledge and experience to identify: [2] identify known or potential failure modes of a product or process, [3] evaluate the failures of a product or process and their effects, [4] assist engineers to initiate corrective actions or preventive measures, and [5] eliminate or reduce the chance of the failures occurring.

In FMEA method, three parameters (severity, occurrence, and detection) are used to describe each failure mode of a product or process. Severity is the seriousness of the failure. Occurrence is the probability or frequency of the failure occurring. Detection is the likelihood of detecting the failure. Each parameter can be assigned a rating from 1 to 10 . Risk priority number (RPN) is the product of the severity, occurrence, and detection ratings. And, the criticality of each failure mode can be generated by the calculation of RPN. The failure having a higher RPN will have a higher priority for corrective action or preventive measure [6].

Fuzzy system is a knowledge-based system which is constructed from expertise and experience in the form of fuzzy IF-THEN rules. Through building knowledgebased model, expert knowledge and judgment could be utilized to make the FMEA assessment method more reasonable and convenient. This approach uses linguistic variables to represent the severity, occurrence, and detection of each failure mode. Each linguistic variable has five linguistic terms to describe it. These linguistic terms are Remote $(R), \operatorname{Low}(L)$, Moderate $(M)$, High $(H)$, and Very High $(V)[7]$.

Fuzzy concept was incorporated to FMEA methodology to allow uncertainty and imprecise information to be included [8]. Fuzzy FMEA has been widely used in many industrial applications as in marine industry [9], engine systems [10] auxiliary feed water system in nuclear power plants [11] and wind turbine assembly manufacturers for risk and reliability analysis [12]. However, research by minimizing rework using fuzzy FMEA has never been done with crumb rubber industries. The aim of this study is get the risk of failure and the level of risk of failure during the crumb rubber production process.

\footnotetext{
* Corresponding author: syahputri.khalida@gmail.com
} 


\section{Methodology}

The study was conducted in one of the companies that produce crumb rubber which is the object of this research is the number of crumb rubber products in rework. The study begins with a direct observation to see and observe the situation at the study site. From the results of observation, determined the formulation of the problem accordance by what is happen to the company. After the formulation of the problem is determined, determined the purpose of research on the problems that occurs. The purpose of the study determined is a solution of the existing problems. Furthermore, collecting the data needed in conducting this research. Data collected are crumb rubber production data and crumb rubber product defects. By both data, data processing is done using fuzzy FMEA method.

Failure mode and effects analysis (FMEA) is known as a systematic and structured way for detecting system modes and evaluating the effects and consequences of failure modes [13]. FMEA is an evaluation technique used to identify and eliminate known and/or potential failures, problems, and errors from a system, process, and/or service before they actually occur [14]. FMEA Fuzzy is used to determine the value of the risk priority number of failures that occurs. The use of this method helps companies in determining which processes should be prioritized in gradual solution delivery to minimize the occurrence of failure in production process.

This method usually begins in review processes of product or system design. Along with the product or system design changes and also gathering information about the product or system performance by testing before manufacturing and field experiences, the results evolved over time. This method is used in decisionmaking during the designing phase of the product or system [15]. The stages in the use of Fuzzy FMEA method begins by identifying the type of defect that has the greatest potential to occur in the production process with the pareto rule. Then analyzed the cause of crumb rubber product defect by cause and effect diagram. After the cause of defect is known, then determine the value of
Risk Priority Number (RPN) by using FMEA method. RPN value obtained through the multiplication of severity rating, occurance, and detection. The calculation of RPN can be done by using the formula.

$$
\mathrm{SS}=\mathrm{S} \times \mathrm{O} \times \mathrm{D}
$$

The value of RPN obtained will be input on the fuzzification process. Through this process, will be obtained fuzzy risk priority number (FRPN). Based on the value of FRPN, the most riskiest cause of defect is found and will be the top priority in making improvement later.

\section{Result and discussion}

\subsection{Identification of defect types}

This identification is carried out to identify defect types that becomes the priority and most riskiest product defects that occurs in the company. This stage is done by sorting each defect types from the largest number of defects to the smallest. Then calculated the percentage of defect and the cumulative percentage of each defect types. Based on the cumulative percentage results, it is determined that defct types should be analyzed further using the pareto rules. The pareto rule used is $80-20$ where $80 \%$ of problems arising from the resulting product come from $20 \%$ cause of defect. The results show that defect types must be analyzed further and become the cause of the problem is a hard crumb rubber and crumb rubber that has fish eyes.

\subsection{Defect causes analysis}

Causes defect analysis of crumb rubber products is done by using the cause and effect diagram. This diagram serves to analyze and find the factors that influence significantly in determining the quality characteristics of the product. A cause and effect diagram for a defect crumb rubber product can be seen on Fig. 1 dan Fig. 2 .

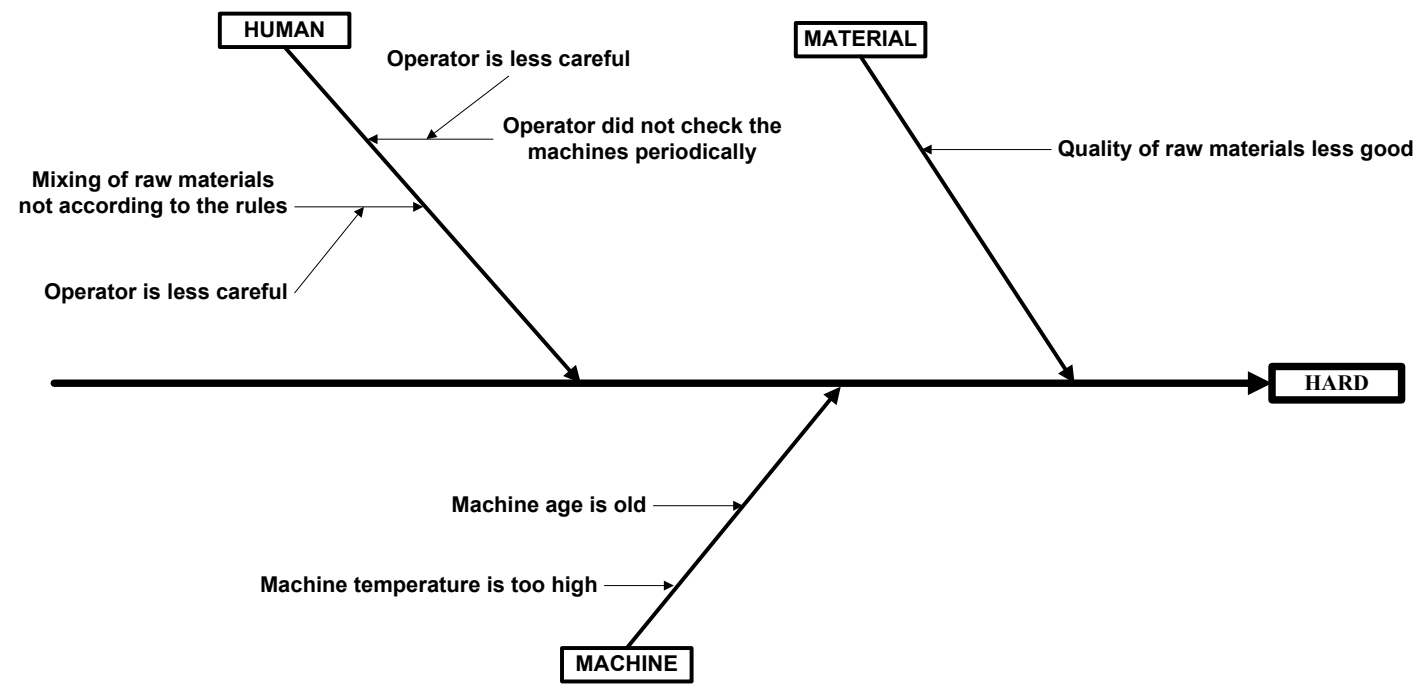

Fig. 1. Cause and effect diagram of hard crumb rubber product defects. 


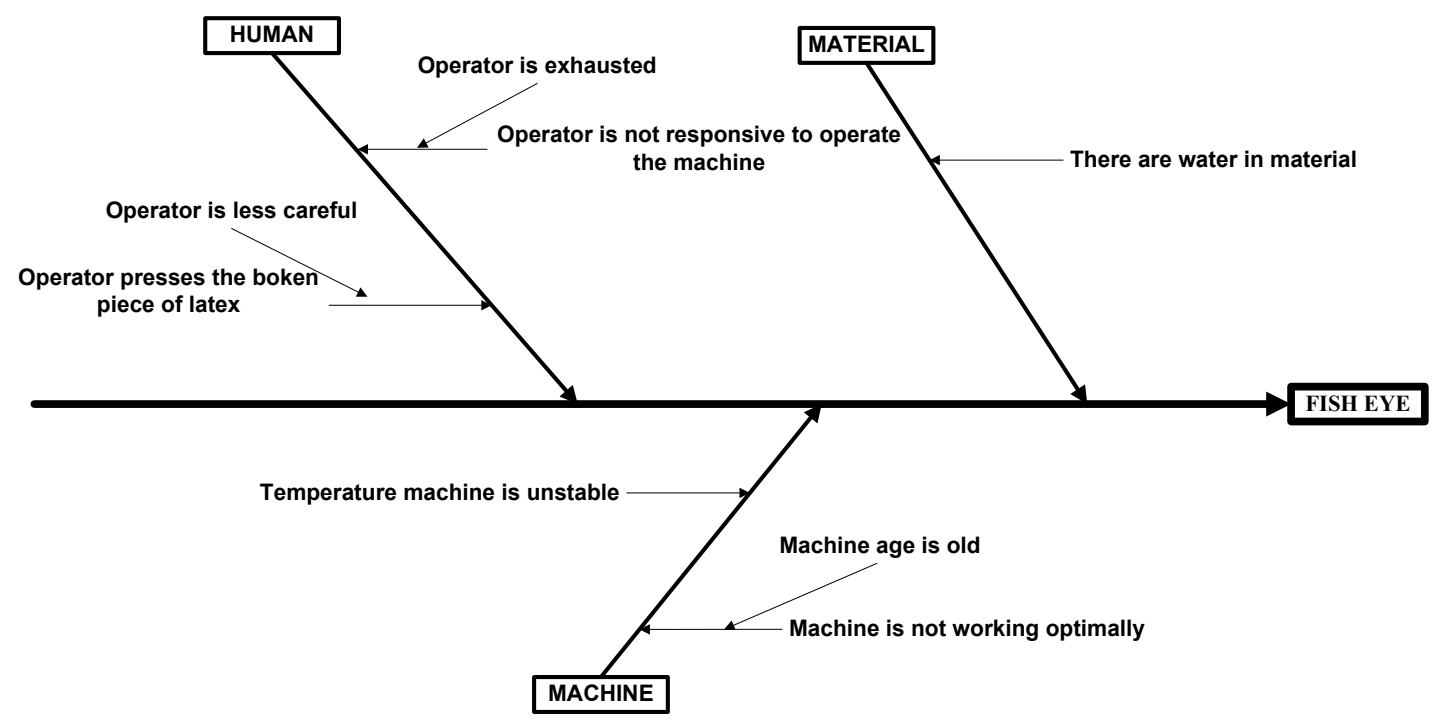

Fig. 2. Cause and effect diagram of crumb rubber product defects with fish eye.

\subsection{Risk priority number by FMEA}

The value of the risk priority number (RPN) can be obtained by first determining the value of failure effects (severity), chance of failure (occurance), and detection of failure (detection).

RPN value obtained through the multiplication of severity rating, occurance, and detection. Based on the calculation, it is found that defect types of hard crumb has a value of RPN about 175 and 90 with a value of $S$ about 5, O consist of 7 and 6, and D consist of 5 and 3 . Besides, defect types of hard crumb rubber with fish eye has a RPN value of 245 and 120 with $\mathrm{S}$ value about 5 , $O$ consist of 7 and 6 , and D consist of 7 and 4 .

\subsection{Fuzzy failure mode and effect analysis}

Fuzzy logic in FMEA is an appropriate way to determine an input space into an output space. Input in this fuzzy logic approach is obtained by the value of failure effect (severity), chance of failure (occurance) and detection failure (detection) of FMEA stage. This process is done using the Mamdani method or often known as the Maximum-Minimum method. Because the input variables are divided into 3 fuzzy sets, ie for variable $S$ (severity), O (occurance) and D (detection) where the output variables have a fuzzy set, ie Fuzzy Risk Priority Number (FRPN). Recapitulation of FMEA fuzzy calculation of crumb rubber product can be seen on Table 1.

Tabel 1. Fuzzy FMEA of crumb rubber product.

\begin{tabular}{|c|c|c|c|c|c|c|c|}
\hline $\begin{array}{l}\text { Failure } \\
\text { Mode }\end{array}$ & Failure Effect & $\mathbf{S}$ & Failure Causes & $\mathbf{O}$ & Detection Method & D & FRPN \\
\hline \multirow[b]{2}{*}{ Hard } & \multirow{2}{*}{$\begin{array}{l}\text { The product can not be processed, } \\
\text { makes disrupting the function of } \\
\text { product as a whole, the product is not } \\
\text { accepted by the consumer and the } \\
\text { hard products can be rework }\end{array}$} & \multirow[b]{2}{*}{5} & $\begin{array}{l}\text { Temperature of } \\
\text { dryer machine is } \\
\text { high }\end{array}$ & 7 & $\begin{array}{l}\text { Checking machine } \\
\text { during the production } \\
\text { process }\end{array}$ & 4 & 491 \\
\hline & & & $\begin{array}{l}\text { Operator did not } \\
\text { check dryer } \\
\text { machine } \\
\text { periodically }\end{array}$ & 5 & $\begin{array}{l}\text { Operator checks the } \\
\text { temperature machine }\end{array}$ & 3 & 366 \\
\hline \multirow[t]{2}{*}{ Fish Eyes } & \multirow{2}{*}{$\begin{array}{c}\text { Display product is not interesting, the } \\
\text { product must be returned by the } \\
\text { consumer and } 100 \% \text { of fish eye can } \\
\text { be rework }\end{array}$} & \multirow[t]{2}{*}{5} & $\begin{array}{l}\text { Operator presses } \\
\text { the broken piece of } \\
\text { latex because of } \\
\text { inserted into the } \\
\text { box }\end{array}$ & 7 & $\begin{array}{l}\text { Pay attention to the } \\
\text { broken piece of latex } \\
\text { when inserted into the } \\
\text { box }\end{array}$ & 7 & 629,32 \\
\hline & & & $\begin{array}{c}\text { Machine is not } \\
\text { working optimally }\end{array}$ & 6 & $\begin{array}{l}\text { Check if the machine } \\
\text { is in good condition } \\
\text { or not }\end{array}$ & 3 & 374,71 \\
\hline
\end{tabular}

Based on the above table, shows that the highest FRPN value about 629.32 by the failure cause of operator presses the broken piece of latex because of inserted into the box and becomes the first priority in making improvement. This result clarifies some previous studies which suggest that the use of FMEA fuzzy is able to overcome problems in minimizing rework, risk assessment, and failure factors [1,8]. Fuzzy FMEA determines the ranking of the factors most at risk of failure based on the value of the fuzzy RPN, which is implemented to make the system more reliable and help maintain sustainable production without rework [1]. 


\section{Conclusions}

Fuzzy FMEA is used to get minimized rework by identifying factors that cause failure and determine the priority level of the risk of number priority (RPN) in crumb rubber process production. From the FMEA results shows that the highest RPN value is the cause of operator presses the broken piece of latex because of inserted into the box is 245 with moderate category, while the fuzzy FMEA results obtained by the highest FRPN value is the cause of operator presses the broken piece of latex because of inserted into the box is 629.32, high-very high category.

Authors would like to thank to Universitas Sumatera Utara forfunding the financial support for publishing this paper.

\section{References}

1. R.K. Sharma, D. Kumar, and P. Kumar, International Journal of Quality \& Reliability Management 22, 9 (2005).

2. D. Bell, L. Cox, S. Jackson, and P. Schaefer, Proceeding of Annual Reliability and Maintainability Symposium, (1992)

3. J.B. Bowles, C.E. Pelaez, Reliability Engineering and System Safety 50, (1995)

4. M. Braglia, M. Frosolini, and R. Montanari, The International Journal of Quality and Reliability Management 20, (2003)

5. K. Jenab, B. S. Dhillon, International Journal of Reliability Quality and Safety Engineering 12, (2005)

6. M. Kumar, S. Kumar, and D. Kumar Dev, International Journal of Engineering Technology, Management and Applied Sciences 5, (2017).

7. R. Huei $Y$ and M. Huan H, Journal of the Chinese Institute of Industrial Engineers 24, 6 (2007)

8. Xu, K., Tang, L.C., Xie, M., Ho, S.L., Zhu, M.L , Reliab. Eng. Syst. Safe. 75, (2002)

9. J. Wang A. Pillay, Reliability Engineering and System Safety 79, (2003)

10. M. Xie S.L. Ho M. L. Zhu K. Xu, L.C. Tang, Reliability Engineering and System Safety 75, (2002)

11. C.M.F. Lapa A.C.F. Guimares, Progress in Nuclear Energy 44, 3(2004)

12. F. Dinmohammadi, M. Shafiee, International Journal of Prognostics and Health Management, (2013)

13. M. Ben Rabha, M.F. Boujmil, M. Saadoun, B. Bessaïs, Eur. Phys. J. Appl. Phys. (to be published)

14. Spath P. L., \& Hickey P, Home study program: Using failure mode and effects analysis to improve patient safety. AORN Journal 78, (2003)

15. S. Karimi T, A. Reza N, S. Abadi, S. Mahdi Vesal, A. Mirzaei \& Khaled Nawaser, International Education Studies 6, 9 (2013) 